\title{
Concerns of stem cell transplant patients during routine ambulatory assessment
}

\author{
This article was published in the following Dove Press journal: \\ Patient Preference and Adherence \\ 3I December 2012 \\ Number of times this article has been viewed
}

\section{Lisa Kennedy Sheldon' \\ Maryum Kazmi' \\ Cynthia Klein² \\ Donna L Berry ${ }^{3}$}

'University of Massachusetts Boston, Boston, MA, ${ }^{2}$ Seattle Cancer Care Alliance, Seattle, WA, ${ }^{3}$ Phyllis Cantor Center for Research in Nursing and Patient Care Services, Dana-Farber Cancer Institute, Boston, MA, USA

Correspondence: Lisa Kennedy Sheldon University of Massachusetts Boston, Boston, 100 Morrissey Boulevard,

Boston, MA 02125, USA

$\mathrm{Tel}+\mathrm{I} 6172875000$

Fax + I 6172877527

Email lisa.kennedysheldon@umb.edu
Background: Stem cell transplant (SCT) is a treatment choice for many hematological malignancies. There is currently a lack of evidence regarding the self-reported concerns of SCT patients before and after SCT.

Aim and design: This exploratory study performed a secondary analysis of self-reported, written concerns of SCT patients before and after transplant to determine patients' concerns. Methods: Content analysis of text box entries of SCT patients collected between 2005 and 2007 at the Seattle Cancer Care Alliance. Text box entries were collected as part of symptom assessment using the Electronic Self-Report Assessment - Cancer instrument. The assessment was presented to 137 patients undergoing SCT at two time points: prior to ambulatory visits before any therapy had begun (T1) and at the first visit after hospital discharge following SCT (T2).

Results: Text box entries were made before $(n=52)$ and after $(n=87)$ the transplant, resulting in 139 text box entries made by 137 patients representing 133 concerns. Using content analysis, the entries were categorized and ranked according to frequency. After symptom concerns, patients ranked work and financial issues the most frequent concerns prior to SCT. After SCT, symptoms remained the most frequently entered area of concern, followed by survival.

Conclusion: Oncology providers need to assess SCT patients for work and financial concerns before and after transplant. Appropriate and timely referrals may ease the burden of these concerns for patients. Thus, assessment of financial and work concerns by the oncology team should be an integral part of quality health care for patients undergoing SCT.

Keywords: self-report, electronic self-report assessment - cancer, cancer, patient concerns

\section{Background}

Stem cell transplant (SCT) is a life-sustaining treatment indicated for some individuals with cancer, hematological malignancies. This secondary data analysis compiled self-reported concerns of adult patients before and after allogeneic and autologous SCT. Data were collected at two time points during a clinical trial: during preparation for SCT before any therapy and during the first clinic visit following hospital discharge after SCT.

\section{Increase in SCTs}

The number of transplants performed in the USA has gradually increased over the last 20 years, particularly in older patients ( $>50$ years old). According to the Center for International Blood and Marrow Transplant Research summary report, there were 7012 allogeneic and 9778 autologous transplants performed in 2009. ${ }^{1}$ The type of SCT depends on the disease, stage, patient's age and overall health, previous treatment or 
recurrence, and the availability of matched donors. SCT may be autologous, using blood-forming cells from the patient, or allogeneic, using cells from a family member, unrelated matched donor, or umbilical cord blood. Several variables have contributed to the increase in SCTs, including additional indications for other diseases, better understanding of the optimal timing of SCT, increased donor availability, and improved supportive care. This trend is also related to the increasing numbers of autologous transplants for multiple myeloma (MM) and non-Hodgkin's lymphoma, both diseases that afflict adults during middle age and later life.

\section{Survival}

SCT provides an increased chance for survival for patients dealing with hematological and other potentially life-shortening diseases. These malignancies include acute lymphocytic leukemia, chronic lymphocytic leukemia, acute myelogenous leukemia, chronic myelogenous leukemia, aplastic anemia, Hodgkin's and non-Hodgkin's lymphomas, and MM. In diseases such as MM, where a cure is almost never achieved using chemotherapy alone, autologous SCT has become the standard of treatment. ${ }^{2}$ According to the Center for International Blood and Marrow Transplant Research, ${ }^{1}$ the 3-year probability of survival in patients with MM between 1998 and 2008 with autologous transplant was $68 \% \pm 1 \%$. Survival rates for other hematological malignancies after an autologous or allogeneic SCT are also on the rise. ${ }^{1}$

\section{Patients' concerns}

SCT is a physically, emotionally, and psychologically overwhelming procedure for both patients and families. ${ }^{3}$ A number of studies have analyzed the concerns of the patients after SCT; ${ }^{4-10}$ however, limited evidence exists regarding the types of concerns patients have at the time of initial consultation for SCT. A study was conducted on 50 potential candidates for autologous or allogeneic transplant at the University of Michigan Comprehensive Cancer Center to screen for anxiety. It was found that $51 \%$ of patients exceeded the threshold score for significant level of distress, according to the Distress Thermometer tool, and anxiety on the Hospital Anxiety and Depression Scale (HADS) during initial consultation. ${ }^{11}$

A pilot study conducted on 80 adults at a comprehensive cancer center in Boston, Massachusetts, assessed psychosocial stress prior to SCT, at first clinic visit after discharge from the hospital and then at 100 days posttransplant using the Spielberger's State Anxiety Inventory and Beck Depression Inventory. ${ }^{12}$ The investigators reported pre-transplant anxiety and/or depression in 55\% of patients. Posttransplant screening was completed in $69 \%$ of the sample patients and $44 \%$ were found to have symptoms of depression, anxiety, or posttraumatic stress disorder. In addition, pre-transplant distress was found to be highly predictive of posttransplant distress.

Patients may require 6 months to 1 year to recover from SCT, limiting their ability to be employed or return to work.

\section{Cost of SCT}

SCT is an expensive treatment and there is wide variation in insurance company coverage, with companies often only paying part of the total expenses. Transplant expenses vary depending on the specifics and type of transplant. Complications can occur before and/or after SCT, further increasing the cost of care. These complications may occur after the conditioning regimen, in which patients receive high-dose chemotherapy and radiation to diminish or eliminate diseased bone marrow, and may include infection, mucositis, nausea, vomiting, pain, and veno-occlusive disease. Complications after the SCT, especially following allogeneic SCT, may occur in the form of graft versus host disease as the patient's immune system works against the host cells.

A study was conducted between 2000 and 2004 by Satio and colleagues at the Dana Farber Cancer Institute/Brigham Women's Hospital on 376 patients receiving high-dose hematopoietic cell transplantation to estimate costs. ${ }^{13}$ The researchers estimated median costs of up to US\$102,574 and 36 days of initial hospitalization for a complicated allogeneic SCT.

\section{Paying for SCT}

Performance of SCT is concentrated in countries with higher governmental health care expenditures, higher gross national income per capita, and good medical resources. Hence, availability of resources, governmental support, and access to transplant centers are the key factors related to global SCT access. ${ }^{14}$ Paying for SCT is recognized as a significant factor in access to care by international investigators. ${ }^{15-17}$

In the USA, the most common method of payment for SCT is via health care insurance. However, the high cost of cancer care has been recognized by researchers and clinicians ${ }^{18,19}$ and highlighted as an important factor in cancer treatment. ${ }^{20}$ With rising copayments for medications as high as $20 \%$ for some medications and other out-of-pocket expenses, people with cancer often find it difficult to pay for health care, despite having some form of health insurance. ${ }^{21}$ 
The American Cancer Society published an extensive report in 2009, entitled Spending to Survive: Cancer Patients Confront Holes in the Health Insurance System, based on a survey of patients with cancer who described their personal experiences with the high cost of cancer care. ${ }^{22}$ The report summarized that high cost-sharing, capitation of benefits, and lifetime maximum expenditure can leave patients responsible for high out-of-pocket expenses. In the case of SCT, the deductibles and out-of-pocket costs related to ambulatory care, follow-up visits and medications can be overwhelming. It is difficult to provide a cost estimate, as each individual insurance policy has its own standard of coverage. More concerning, employer-based health insurance may not cover catastrophically high health care costs if employees become too ill. Additionally, cancer survivors are often unable to find adequate and affordable health insurance after diagnosis and treatment.

The American Cancer Society report ${ }^{22}$ also reviewed other factors that can leave people with cancer without affordable insurance. Such factors include waiting periods, strict restrictions on eligibility, and/or delayed application for public programs, meaning that patients, who are often too ill to work, are left without health care insurance. Additionally, insurance companies may not notify patients when they reach their lifetime maximum spending limit, leaving patients responsible for costs incurred in the future. Patients may also face tremendous consequences from financial responsibilities, including inability to continue with life-sustaining treatment, bankruptcy, or even loss of their home or life savings.

In the past, discussions regarding cost of care have not been a priority. In some instances, these discussions have even been avoided by health care providers and patients. ${ }^{23-26}$ Schrag and Hanger reported that physicians viewed these discussions as an important component of care; however, when they did not have the resources to help the patients, many of them indicated that they viewed such discussion as meaningless. ${ }^{26}$ In consequence, this lack of communication may result in SCT patients finding themselves unprepared for the expenses of future care.

\section{Patient assessment}

Comprehensive assessment of patients by health care providers is an important method through which to identify not only patient symptoms but also troublesome concerns before, during, and after SCT. Accurate assessment is necessary to prepare patients for their future health care needs. Electronic self-report tools have been developed to make these assessments efficient, detailed, easily understandable, and to incorporate patients' priority needs in treatment plans. ${ }^{27}$ One type of self-report, the Electronic Self-Report Assessment - Cancer (ESRA-C), has been used to assess patient symptoms and quality of life prior to ambulatory oncology visits in both adults ${ }^{28}$ and adolescents..$^{29}$ In a large randomized trial, ESRA-C summary reports of the participants' reports were provided to health care providers immediately prior to clinic visits and were found to significantly increase the frequency of discussing troublesome symptoms and quality of life issues. ${ }^{30}$

\section{Purpose}

The study reported here was an exploratory secondary analysis of data collected in the ESRA-C trial, between 2005 and 2007, at a comprehensive cancer center in the US Pacific Northwest. The focus of this study was on the concerns of SCT patients that were self-reported either as "most important" or that "had not been covered" in the assessment regarding symptom experiences.

\section{Methods}

Data were collected at two time points: during ambulatory oncology visits before the start of treatment (T1) and then at the first clinic visit after hospital discharge for patients who had undergone SCT as an inpatient (T2) ${ }^{30}$ Content analyses of the text box entries were performed to determine categories of concerns at the two time points.

Institutional review board approval was obtained from University of Massachusetts, Boston, to analyze these deidentified data. During the original study, ESRA-C was presented to 137 patients undergoing SCT prior to ambulatory visits at two time points: before any therapy had begun (T1) and at the first visit after hospital discharge after the SCT (T2), approximately 1 month after autologous transplant. Validated symptom and quality of life questionnaires were presented within the web-based ESRA-C instrument, notably the Quality of Life Questionnaire C-30, ${ }^{31}$ which included one item assessing financial difficulties. Free text boxes appeared for each participant at the end of the ESRA-C assessment. The instructions asked the participant to type the "two most important concerns" or "anything else ... we haven't covered here."

\section{Results}

Participants were aged between 19 and 75 years old and the mean age was 49. Table 1 lists the characteristics of the sample. The majority were male, Caucasian, and college graduates. 
Table I Demographic characteristics; $\mathrm{n}=137$

\begin{tabular}{ll}
\hline Variables & $\mathbf{n}(\%)$ \\
\hline Age (years) & \\
Mean age $=49$ & \\
Standard deviation = 13.24 & \\
Gender & \\
$\quad$ Male & $82(60.7)$ \\
Female & $55(39.3)$ \\
Race & \\
Black & $1(0.72)$ \\
Asian & $2(1.46)$ \\
Native American & $4(2.91)$ \\
Mixed race & $6(4.37)$ \\
Caucasian & $124(90.5)$ \\
Education & \\
9th-I2th grade & $32(23.4)$ \\
2 year college & $38(27.7)$ \\
4 year college & $39(28.5)$ \\
Graduate degree & $28(20.4)$ \\
& \\
Type of transplant & \\
Autologous & \\
Allogeneic & $56(62.77)$ \\
\hline
\end{tabular}

Text box entries were made before $(\mathrm{n}=52)$ and after $(n=87)$ the transplant, resulting in 139 text box entries made by 137 patients. Two patients wrote "none" in the text boxes. Six comments were general statements about hospital services received during their inpatient stay. Using content analysis, the remaining 133 concerns were categorized then ranked according to their frequency.

The most frequent concerns expressed by the patients were categorized as quality of life, symptom management, family and caregiver strain, survival, work/financial issues, depression/feeling down, and physical appearance (Table 2). Some patients entered more than one concern using the same text box.

Before the transplant (T1), symptom management issues were most frequently entered and concerns regarding work and finances were the second most common entries. One patient commented that the financial cost associated with SCT was "ridiculous," while another patient mentioned surviving the SCT and financial debt being the only main issues. At the first appointment after hospital discharge (T2), the most frequently entered concern was symptom management; concerns regarding survival were the second most common entries.

\section{Discussion}

This analysis revealed that, second only to symptom issues, work and financial concerns were present for both allogeneic and autologous SCT recipients prior to their transplant.
Table 2 Self-reported concerns and frequencies before (TI) and after (T2) autologous or allogeneic stem cell transplant (SCT) for 137 participants

\begin{tabular}{|c|c|c|c|}
\hline Concerns & $\begin{array}{l}\text { Number } \\
\text { of concerns } \\
\text { (autologous } \\
\text { SCT) }\end{array}$ & $\begin{array}{l}\text { Number } \\
\text { of concerns } \\
\text { (allogeneic } \\
\text { SCT) }\end{array}$ & $\begin{array}{l}\% \text { of entries } \\
\text { for both } \\
\text { types of } \\
\text { SCT }\end{array}$ \\
\hline \multirow[t]{2}{*}{ Symptom management } & $\mathrm{TI}=5$ & $\mathrm{TI}=20$ & $\mathrm{TI}=18.8$ \\
\hline & $\mathrm{T} 2=4$ & $\mathrm{~T} 2=14$ & $\mathrm{~T} 2=13.5$ \\
\hline \multirow[t]{2}{*}{ Work/financial } & $\mathrm{TI}=8$ & $\mathrm{TI}=8$ & $\mathrm{TI}=12.0$ \\
\hline & $\mathrm{T} 2=1$ & $\mathrm{~T} 2=\mathrm{I}$ & $\mathrm{T} 2=1.5$ \\
\hline \multirow[t]{2}{*}{ Quality of life } & $\mathrm{TI}=2$ & $\mathrm{TI}=2$ & $\mathrm{TI}=3.0$ \\
\hline & $\mathrm{T} 2=\mathrm{I}$ & $\mathrm{T} 2=\mathrm{I}$ & $\mathrm{T} 2=1.5$ \\
\hline \multirow[t]{2}{*}{ Family/caregiver } & $\mathrm{TI}=3$ & $\mathrm{TI}=6$ & $\mathrm{TI}=6.8$ \\
\hline & $\mathrm{T} 2=\mathrm{I}$ & $\mathrm{T} 2=\mathrm{I}$ & $\mathrm{T} 2=1.5$ \\
\hline \multirow[t]{2}{*}{ Survival } & $\mathrm{TI}=0$ & $\mathrm{TI}=3$ & $\mathrm{TI}=2.3$ \\
\hline & $\mathrm{T} 2=0$ & $\mathrm{~T} 2=8$ & $\mathrm{~T} 2=6.0$ \\
\hline \multirow[t]{2}{*}{ Depression/feeling down } & $\mathrm{TI}=\mathrm{I}$ & $\mathrm{TI}=3$ & $\mathrm{TI}=3.0$ \\
\hline & $\mathrm{T} 2=0$ & $\mathrm{~T} 2=0$ & $\mathrm{~T} 2=0$ \\
\hline \multirow[t]{2}{*}{ Physical appearance } & $\mathrm{TI}=0$ & $\mathrm{TI}=\mathrm{I}$ & $\mathrm{TI}=0.8$ \\
\hline & $\mathrm{T} 2=\mathrm{I}$ & $\mathrm{T} 2=2$ & $\mathrm{~T} 2=2.3$ \\
\hline \multirow[t]{2}{*}{ Other } & $\mathrm{TI}=10$ & $\mathrm{TI}=\mathrm{I} 4$ & $\mathrm{TI}=18 . \mathrm{I}$ \\
\hline & $\mathrm{T} 2=3$ & $\mathrm{~T} 2=9$ & $\mathrm{~T} 2=9.0$ \\
\hline \multirow[t]{2}{*}{ Total concerns (I33) } & $\mathrm{TI}=29$ & $\mathrm{TI}=57$ & $\mathrm{TI}=64.7$ \\
\hline & $\mathrm{T} 2=11$ & $\mathrm{~T} 2=36$ & $\mathrm{~T} 2=35.3$ \\
\hline
\end{tabular}

Abbreviations: TI, Concerns mentioned before going for SCT; T2, Concerns mentioned at first visit after hospital discharge.

This finding suggests that the patients were dealing with the financial aspects regarding treatment at a time when the clinical focus was to prepare them for a high morbidity therapy. Despite having answered the financial difficulty item included in the Quality of Life Questionnaire C-30 component of the ESRA-C, these participants made additional mention of these concerns in the free text boxes. This finding indicates the serious and stressful nature of financial concerns for patients preparing for SCT. Patients' entries in the text boxes were explicit about the feelings of frustration, helplessness, and anger relating to financial concerns.

Given the aging demographic of SCT patients, financial and work concerns may be a priority for this population. While some patients may be employed and financially stable at the beginning of the treatment, these circumstances may change during the transplant and recovery process, draining resources and diminishing capacity. Patients may be unable to work because of treatment-related symptoms such as fatigue and weakness related to high-dose chemotherapy regimens. ${ }^{32}$ The inability to work may also drastically change their socioeconomic status and/or reduce financial resources. For the uninsured, $\mathrm{SCT}$ is a costly procedure and may actually affect their ability to access this care. People who are underinsured or lose insurance due to their disease 
may also find themselves unable to continue with treatments and/or follow-up visits. Therefore, the financial needs of SCT patients may change over the course of treatment and during survivorship, requiring ongoing assessment during these times.

Communication regarding the cost of cancer treatment for patients may have an enormous impact on the quality of health care decision-making. The American Society of Clinical Oncology published guidelines in 2009 regarding patient-provider communication about the cost of cancer care and emphasized that such discussions are an integral part of high-quality care. ${ }^{19}$ The National Marrow Donor Program recommended that all patients prepare a personalized report including their current monthly income, household expenses, and additional indirect expenses. ${ }^{33}$ In addition, it recommended that patients contact their insurance carrier to find out their terms and limitations prior to contacting the transplant center. This information also provides data to tailor educational sessions and provide appropriate financial counseling.

A team approach is the key to assessment of the financial concerns of patients undergoing SCT. Despite the recognition of these concerns, the decision regarding which oncology care provider is responsible for this assessment differs according to institution and practice. ${ }^{25}$ In some cases, patients may not want to discuss these concerns with their physicians, preferring to talk about them with someone not involved in decision-making about the treatment. ${ }^{21}$ Nurses, as patient advocates, can play a crucial role in identifying patients' financial concerns both before and after transplant and by making appropriate referrals to social workers or financial counselors. ${ }^{25}$ Finally, when patients are preoccupied with financial concerns, their understanding of important education such as medication regimens may suffer. They may also experience increased stress, which could affect their future health and recovery.

Thus, the findings of this exploratory study highlight the substantial symptom management and financial concerns expressed by SCT patients before and after transplant. Assessing financial concerns should be a priority before SCT. If not addressed, patients may feel isolated in dealing with these concerns, interfering with their ability to comprehend complex treatment.

\section{Limitations}

This secondary analysis is limited by having access only to variables collected in the parent clinical trial. Further, the patients in this secondary analysis only received SCT as inpatients and their concerns may not reflect those of patients who undergo outpatient SCT. Future analyses of financial concerns would be best informed by including other variables, such as insurance type, in a multivariable model. Finally, the sample included primarily educated, non-Hispanic, Caucasians at a single institution, precluding generalization beyond these demographics.

\section{Conclusion}

New directions in health care systems see patient-centered care as an integral and necessary part of quality health care. ${ }^{34}$ It has been proposed that assessment of financial constraints - including the financial impact of cancer on patients and families and loss of job or insurance - costs vs benefits, and societal impact be among the key outcomes of patient-centered care. ${ }^{35}$ Given the frequency of financial concerns of patients undergoing SCT, oncology health care providers need to take an active role in the assessment of financial concerns of their patients to ensure quality health care.

Ideally, assessment of financial concerns should begin at diagnosis and continue through treatment and survivorship. However, the course of treatment for SCT patients may be unpredictable. The oncology health care team, including nurses, physicians, social workers, and financial counselors, share the responsibility to ensure quality health care for these patients, which should include continuous assessment of financial and work concerns. Oncology nurses are ideally positioned to advocate, assess, and prioritize this communication. While helping patients to manage these concerns, oncology nurses may also advocate for change in institutional policies related to financial planning and counseling of all patients receiving SCTs. Therefore, assessment of financial and work concerns by oncology health care providers should be an integral part of care for patients undergoing SCT, across the care trajectory.

\section{Disclosure}

The authors report no conflicts of interest in this work.

\section{References}

1. Pasquini MC, Wang Z. Current Use and Outcome of Hematopoietic Stem Cell Transplantation: CIBMTR Summary Slides, 2011 [slide presentation]. Milwaukee, WI: Center for International Blood and Marrow Transplant Research; 2011. Available from: http://www.cibmtr.org/ slides. Accessed November 10, 2012.

2. Bensinger IW. Role of autologous and allogeneic stem cell transplant in myeloma. Leukemia. 2009;23(3):442-448.

3. Moore WC, Rauch PK. Addressing parenting concerns of bone marrow transplant patients: opening (and closing) Pandora's box. Bone Marrow Transplant. 2006;38(12):775-782.

4. Rusiewicz A, DuHamel KN, Burkhalter J, et al. Psychological distress in long-term survivors of hematopoietic stem cell transplantation. Psychooncology. 2008;17(4):329-337. 
5. Mosher CE, DuHamel KN, Rini C, Corner G, Lam J, Redd WH. Quality of life concerns and depression among hematopoietic stem cell transplant survivors. Support Cancer Care. 2011;19(9): 1357-1365.

6. Kav S, Aslan O, Tekin F, et al. Quality of life and difficulties of patients encountered after autologous stem cell transplantation. J BUON. 2009;14(4):673-680.

7. Stephens M. The lived experience post-autologous haematopoietic stem cell transplant (HSCT): a phenomenological study. Eur J Oncol Nurs. 2005;9(3):204-215.

8. Bhatia S, Robison LL, Francisco L, et al. Late mortality in survivors of autologous hematopoietic-cell transplantation: report from the Bone Marrow Transplant Survivor Study. Blood. 2005;105(11):4215-4222.

9. Bhatia S, Francisco L, Carter A, et al. Late mortality after allogeneic hematopoietic cell transplantation and functional status of long-term survivors: report from the Bone Marrow Transplant Survivor Study. Blood. 2007;110(10):3784-3792.

10. Sanders JE, Hoffmeister PA, Storer BE, Appelbaum FR, Storb RF, Syrjala KL. The quality of life of adult survivors of childhood hematopoietic cell transplant. Bone Marrow Transplant. 2010;45(4): 746-754.

11. Trask PC, Paterson A, Riba M, et al. Assessment of psychological distress in prospective bone marrow transplant patients. Bone Marrow Transplant. 2002;29(11):917-925.

12. Lee SJ, Loberiza FR, Antin JH, et al. Routine screening for psychosocial distress following hematopoietic stem cell transplantation. Bone Marrow Transplant. 2005;35(1):77-83.

13. Satio MA, Cutler C, Zahrieh D, et al. Costs of allogeneic hematopoietic cell transplantation with high-dose regimens. Biol Blood Marrow Transplant. 2008;14(2):197-207.

14. Gratwohl A, Baldomero H, Aljurf M, et al; Worldwide Network of Blood and Marrow Transplantation. Hematopoietic stem cell transplantation: a global perspective. JAMA. 2010;303(16):1617-1624.

15. Abdel-Rahman F, Hussein AA, Rihani R, et al. Bone marrow and stem cell transplantation at King Hussein cancer center. Bone Marrow Transplant. 2008;42 Suppl 1:S89-S91.

16. Benchekroun S, Harif M, Madani A, Quessar A, Zafad S, Rachid R. Present and future of hematology and stem cell transplantation in Morocco. Bone Marrow Transplant. 2008;42 Suppl 1:S106-S108.

17. Issaragrisil S. Hematopoietic stem cell transplant in Thailand. Bone Marrow Transplant. 2008;42 Suppl 1:S114-S138.

18. Wagner L, Lacey MD. The hidden costs of cancer care: an overview with implications and referral resources for oncology nurses. Clin $J$ Oncol Nurs. 2004;8(3):279-287.

19. Meropol NJ, Schrag D, Smith TJ, et al; American Society of Clinical Oncology. American Society of Clinical Oncology guidance statement: the cost of cancer care. J Clin Oncol. 2009;27(23):3868-3874.

20. Tangka FK, Trogdon JG, Richardson LC, Howard D, Sabatino SA, Finkelstein EA. Cancer treatment cost in the United States: has the burden shifted over time? Cancer. 2010;116(14):3477-3484.
21. McFarlane J, Riggins J, Smith TJ. SPIKE\$: a six-step protocol for delivering bad news about the cost of medical care. J Clin Oncol. 2008; 26(25):4200-4204.

22. Schwartz K, Claxton G, Martin K, Schmidt C. Spending to Survive: Cancer Patients Confront Holes in the Health Insurance System. Menlo Park, CA and Atlanta, GA: Henry J Kaiser Family Foundation and American Cancer Society; 2009. Available from: http://www.kff.org/ insurance/upload/7851.pdf. Accessed November 10, 2012.

23. Alexander GC, Casalino LP, Meltzer DO. Patient-physician communication about out-of-pocket costs. JAMA. 2003;290(7):953-958.

24. Alexander GC, Casalino LP, Tseng CW, McFadden D, Meltzer DO. Barriers to patient-physician communication about out-of-pocket costs. J Gen Inter Med. 2004;9(8):856-860.

25. Mathews M, Park AD. Identifying patients in financial need: cancer care providers' perceptions of barriers. Clin J Oncol Nurs. 2009;13(5): 501-505.

26. Schrag D, Hanger M. Medical oncologists' views on communicating with patients about chemotherapy costs: a pilot survey. $J$ Clin Oncol. 2007;25(2):233-237.

27. Berry DL, Blumenstein BA, Halpenny B, et al. Enhancing patientprovider communication with the electronic self-report assessment for cancer: a randomized trial. J Clin Oncol. 2011;29(8):1029-1035.

28. Wolpin S, Berry D, Austin-Seymour M, et al. Acceptability of an Electronic Self-Report Assessment Program for patients with cancer. Comput Inform Nurs. 2008;26(6):332-338.

29. Wu WW, Johnson R, Schepp KG, Berry DL. Electronic self-report symptom and quality of life for adolescent patients with cancer: a feasibility study. Cancer Nurs. 2011;34(6):479-486.

30. Berry DL, Blumenstein BA, Halpenny B, et al. Enhancing patientprovider communication with the electronic self-report assessment for cancer: a randomized trial. J Clin Oncol. 2011;29:1029-1035.

31. Ringdal GI, Ringdal K. Testing the EORTC Quality of Life Questionnaire on cancer patients with heterogeneous diagnoses. Qual Life Res. 1993;2(2):129-140.

32. Mosher CE, Redd WH, Rini CM, Burkhalter JE, DuHamel KN. Physical, psychological, and social sequelae following hematopoietic stem cell transplantation: a review of the literature. Psychooncology. 2009;18(2):113-127.

33. National Marrow Donor Program. Planning for transplant costs [web page on the Internet]. Minneapolis, MN: National Marrow Donor Program; nd. Available from: http://www.marrow.org/PATIENT/ Plan_for_Tx/Planning_for_Tx_Costs/index.html\#Insurance. Accessed September 9, 2011

34. Perocchia RS, Hodorowski JK, Williams LA, et al. Patient-centered communication in cancer care: the role of the NCI's Cancer Information Service. J Cancer Educ. 2011;26(1):36-43.

35. Ganz PA. What outcomes matter to patients: a physician-researcher point of view. Med Care. 2002;40(Suppl 6):III11-III19.
Patient Preference and Adherence

\section{Publish your work in this journal}

Patient Preference and Adherence is an international, peer-reviewed, open access journal focusing on the growing importance of patient preference and adherence throughout the therapeutic continuum. Patient satisfaction, acceptability, quality of life, compliance, persistence and their role in developing new therapeutic modalities and compounds to

\section{Dovepress}

optimize clinical outcomes for existing disease states are major areas of interest. This journal has been accepted for indexing on PubMed Central. The manuscript management system is completely online and includes a very quick and fair peer-review system. Visit http://www.dovepress.com/ testimonials.php to read real quotes from published authors. 